\title{
THE PROFILE OF PATIENTS WITH SCHIZOPHRENIA WHO ATTEMPTED SUICIDE
}

\author{
Isjanovski Viktor, ${ }^{1}$ Hadjihamza Kadri ${ }^{2}$, Raleva Marija ${ }^{2}$, \\ ${ }^{1}$ Psychiatric hospital "Skopje"-Skopje, Macedonia \\ ${ }^{2}$ University Psychiatric Clinic, Medical faculty, Skopje, Macedonia \\ E-mail: viktorisjanovski@yahoo.com
}

\begin{abstract}
Introduction: Suicide is a complex phenomenon, and deliberate act of taking one's own life, associated with numerous and various biological, social and psychological factors. It is an important psychopathological entity and one of the most demanding clinical problems, which psychiatrists face in their everyday practice, especial in schizophrenic patients. According to literature data, the number of suicides of schizophrenic patients has been increasing in recent decades
\end{abstract}

Objectives: The aim of this study was to determinate the profile of patients with schizophrenia who attempted suicide in the Psychiatric hospital "Skopje"-Skopje, R.Macedonia.

Methods: The study included 114 patients with schizophrenia, $47.4 \%(n=54)$ of them attempted suicide, $52.6 \%(60)$ was group consists of patients with schizophrenia who is not registered for suicide attempt, nor the existence of suicide idea. Psychiatric diagnosis of schizophrenia was based on ICD-10 criteria.

Results: Based on the investigation of patients with schizophrenia who attempted suicide, we obtained a typical profile as follows: middle-aged person(31.4 average years), single (61,1\% were not married, $44.4 \%$ live alone), $(79.5 \%)$ unemployed, repeatedly hospitalized and history of suicide attempts, attempting suicide using a violent method (poisoning $-55.5 \%$, drowing- $-7.4 \%$, hanging- $-9.2 \%$, slashing their wrists $-16.6 \%$, jumped from height- $5.5 \%$ etc.) after more than tree weeks of hospital treatment and out of hospital.

Keywords: suicide; schizophrenia; characteristics

\section{Academic Discipline And Sub-Disciplines:medicine-psychiatry}

\section{Council for Innovative Research}

Peer Review Research Publishing System

Journal: International Journal of Research in Education methodology

Vol . 6, No.3

iiremeditor@gmail.com

www.ijrem.com 


\section{Introduction:}

Suicide is a complex phenomenon, and deliberate act of taking one's own life, associated with numerous and various biological, social and psychological factors. It is an important psychopathological entity and one of the most demanding clinical problems, which psychiatrists face in their everyday practice, especial in schizophrenic patients ${ }^{[1]}$. According to literature data, the number of suicides of schizophrenic patients has been increasing in recent decades ${ }^{[2]}$.

Research has shown that approximately $80 \%$ of people who attempted suicide have schizophrenia, $90 \%$ have a mental disorder, which undoubtedly supports the assumption of an association between psychiatric diagnosis and suicide ${ }^{[1-2]}$. Research has shown that the suicide rate among patients with schizophrenia is seven to ten times higher than among general population ${ }^{[1-2]}$. According Smalc VF. ${ }^{[3]}$ suicidality is a very important and frequent event in schizophrenic patients, occurring in up to $50 \%$ of patients during lifetime, and $20 \%$ of schizophrenic patients end with suicide. Suicides in schizophrenic patients, although sharing some characteristics with suicides in general population, have also specific features for this particular diagnostic group. As many as 1 out of 4 persons with schizophrenia attempts suicide, some even while they are under psychiatric care. Specialists in the study of suicide outline risk factors for suicide in schizophrenic patients and the implications for preventive strategies. Suicide is a major cause of death among patients with schizophrenia, with young adulthood to midlife being the age range of greatest risk. A past history of suicide attempts is common among schizophrenic suicide victims, as are affective symptomatology and feelings of hopelessness and demoralization ${ }^{[4]}$. Active paranoia may increase risk, whereas negative symptoms may decrease the risk of selfdestructive acts in schizophrenic patients. Many suicides occur during hospitalization or shortly after discharge. Methodical assessment of suicidal ideation and aggressive treatment with psychological, social, and pharmacologic approaches are vital aspects of patient management.

\section{Subjects and methods:}

The study included 114 patients hospitalized in the Psychiatric hospital "Skopje" with diagnosis schizophrenia. The data were collected (sex, age at the time of suicide, marital and employment status) as well as the data on clinical characteristics (psychiatric diagnosis and duration of illness) place and methods of committing suicide, legal aspects of hospitalization (voluntary or involuntary) and family history. Patient data were collected retrospectively from medical records and present. Psychiatric diagnosis of schizophrenia was based on ICD-10 criteria. From the statistical methods were used percent, average, standard deviation, OR and $\mathrm{x}^{2}$-test.

\section{Results:}

During the observation period, 114 patients have diagnosis schizophrenia, suicide attempts are registration in $47.4 \%$ $(n=54)$ of the patients (tab-fig.1). Among the patients who attempted suicide, there were $36(66,7 \%)$ men and 18(33,3\%) women, there is statistical difference between men and women $(\mathrm{p}=0.0009)$. We register statistically significant relationship between the attempted suicide and $\operatorname{sex}\left(x^{2}=3.9, p=0.04\right) .61 .1 \%(33)$ were not married, they were singled, $44.4 \%$ live alone and $16.6 \%$ with their parents (tab2). There is statistical difference between men and women $(p=0.0009)$. We register statistically significant relationship between the attempted suicide and modalities of marital status $\left(x^{2}=3.9, p=0.04\right)$. According OR (odds ratio) marital status of patients reduces the risk of suicide (OR=0.33(0.12<OR<0.93, $\mathrm{Cl95} \%$ ). We register statistically significant relationship between the attempted suicide and living alone $\left(x^{2}=4.77, p=0.028\right)$. Living alone, according to the OR is statistically significant risk that increases the chance of suicide in patients with schizophrenia twice. $(\mathrm{OR}=2.40(1.01<\mathrm{OR}<5.74, \mathrm{Cl} 95 \%)$. Living in or with a family, according to OR is statistically significant reduces the risk for registration of suicide in schizophrenia $(\mathrm{OR}=0.42(0.17<\mathrm{OR}<0.99, \mathrm{Cl95} \%)$. The average age were $31.4( \pm 9.3)$ y., 30 patients were in the age group less than $25 \mathrm{y} ., 11$ in the 26-35 age group, 13 were aged over $36 \mathrm{y}$. , when they have their attempted of suicide (tab2). As many as 25(46.3\%) patients were unemployed, was employed, now is not 18(33.3\%) and only 8 were employed (tab.2) We register statistically significant relationship between unemployment and registration of suicide in people with schizophrenia $\left(x^{2}=5.76\right.$ for $\left.p=0,029\right)$ Unemployment according to OR relationship is statistically significant risk increases the chance of registration suicide in patients suffering from schizophrenia for three times $(O R=$ $2.92(1.10<\mathrm{OR}<7.88, \mathrm{Cl} 95 \%)$.

Most of the patients with schizophrenia who attempted suicide had already been hospitalized at least twice, average of previous hospitalizations are $4.4 \pm 3,7$, with one and maximum 13 times(tab.3). There is a positive correlation between the number of hospitalizations and the increase of attempted suicide $-r=0.3118, p=0.022$. With respect to the duration of illness, most of the patients had been chronic patients who suffered from schizophrenia for more than five years-70,4\%, the average duration of disease was18 years. As for the hospitalization duration, most of the patients who attempted suicide were hospitalized for up tree weeks. Majority was hospitalized voluntarily. Clinical types of schizophrenia were: 42 , $6 \%$ paranoid, non-difference and non-specific was $22.2 \%$ and so on (tab3) 
The suicide methods, most patients used poisoning with medicaments and acid-59.2\% as a suicide methods, drowing$7,4 \%$, hanging- $9.2 \%$, and slashing their wrists- $16,6 \%$ whereas smaller number attempted suicide by jumping in front of vehicle(car, bus, train), used electric current, jumped from height, stabbing him/herself with knife, $-20.4 \%($ tab.3). All of the patients who attempted suicide had earlier suicide attempts, and only 5(9.3\%) patients had family history of suicide (tab3). We register statistically significant relationship between suicide attempts in families and registration suicide in patients suffering from schizophrenia Fisher exact 2 tailed $p$ value- $p=0,042$. All attempted suicide were outside of hospital.

\section{Discussion:}

The obtained data could indicate a more severe long-term prognosis of schizophrenia patients.

In our study, suicide was attempted $64,35 \%$ in men, there is statistical difference between men and women $(p<0.05)$, whereas in general population, man attempted suicide three times more often than women.. Brecic ${ }^{[1]}$ also found no gender difference in suicides. On the other hand, other authors reported that man attempted suicide more frequently ${ }^{[1,5-8] \text {. }}$

Although patients with paranoid-42.6\%, non-difference and non-specific $(22,2 \%)$ clinical types of schizophrenia were relative majority among hospital patients. This result is in accordance with the findings reported by other authors. Fenton and colleges ${ }^{(9-11)}$ in theirs studies had find among the patients with schizophrenia, $50 \%$ had the paranoid subtype, $42,8 \%$ had undifferentiated schizophrenia, and $7,2 \%$ had the disorganized type. Active paranoia may increase risk, whereas negative symptoms may decrease the risk of self-destructive acts in schizophrenic patients ${ }^{[4]}$.

As was observed in our sample, a past history of suicide attempts is common in attempts suicides with schizophrenia, and may be the most prominent predictor of subsequent death. We found that most patients who attempted suicide had already attempted suicide, which is in accordance with previous reports on suicide attempts as the most important predictive factor $^{(12-16)}$. These patients should be under close supervision. A past history of suicide attempts is common among schizophrenic suicide victims, as are affective symptomatology and feelings of hopelessness and demoralization ${ }^{[4]}$. According some authors ${ }^{[14,17,18]}$ and their informants and records documented a past history of suicide attempts were in $75 \%$ of victims. Seventy-one percent of Finnish schizophrenics who committed suicide had a past history of suicide attempts ${ }^{[13]}$. Allebeck and colleagues ${ }^{[16-17]}$ noted this association to be especially strong among women.

Individuals with schizophrenia have a shortened life expectancy ${ }^{[19])}$. Compared with both the general population and persons with other mental disorders, these patients have increased mortality risk due to physical illness, accidents, and other causes of violent death, especially suicide ${ }^{[20-21]}$. Studies estimate that from $9 \%$ to $24 \%$ of individuals with schizophrenia will die by their own hand ${ }^{[20-23]}$.

According Caldwell ${ }^{[22-23]}$ in their study, mean age was 36.5 ( \pm 12.0$)$ years. Fourteen $(70 \%)$ were single, 3 were married, 2 were divorced, and 1 was widowed. Five (25\%) lived alone, while the remainder lived with other family or friends. The percent were similar to our findings. Some evidence supports that being unmarried, socially isolated, and unemployed are risk factors for suicide among schizophrenics as well ${ }^{[24-26]}$.

Violent suicide methods - poisoning with medicaments and acid - 59.2\%, drowing-7,4\%, slashing their wrists and hanging-16,7\%, stabbing him/ herself with knife, electric current, jumping in front of moving vehicle, jumping from a height were used in all suicide cases in our study. These data are some what different from those for general population, where $51 \%$ suicides are attempted by hanging, $18 \%$ with firearms and $7 \%$ by jumping from height. Jumping from a height was most frequent method in the patient sample from Vrapce Psychiatric Hospital ${ }^{[1]}$. Our results are very similar to these data. According other study ${ }^{[12]}$, the schizophrenic patients tended to use violent methods to take their lives: 6 (30\%) used a firearm, 5 hanged themselves, 4 jumped from a height, and the remainder used a variety of other means (drowning, drug ingestion, carbon monoxide poisoning, exposure, and self-immolation). According to literature data, the method of attempting suicide is greatly determined by the availability of methods.

The mean duration of illness was over 5 years, had an average of 3.9 lifetime psychiatric admissions. Studies indicate that schizophrenic patients who commit suicide tend to have a relatively more chronic course of illness, with acute exacerbations ${ }^{[14,18,19]}$. Among 92 schizophrenic suicides identified in the Finnish National Suicide Prevention Project, the mean duration of illness was 15.5 years, and victims had an average of 7.9 lifetime psychiatric admissions ${ }^{[14]}$. HavakiKontaxaki and colleagues ${ }^{[15]}$ found a mean duration of illness of 19.3 ( \pm 8.8 ) years for suicide completers, compared with 13.5 ( \pm 9.9 ) years for schizophrenic controls, a significant difference. Cheng and others ${ }^{[12]}$ found that, compared with no suicidal schizophrenics, suicide completers had more frequent psychiatric hospitalizations. Westermeyer and Harrow ${ }^{[24]}$ suggested that a gradual onset of illness over time may also place schizophrenic patients at risk for suicide. Most of the patients in Vrapce ${ }^{[1]}$ samples were unmarried and unemployed, with long duration of illness and large number of previous hospitalizations(6,3 on average), which are well-known risk factors for attempting suicide.

Many suicides occur during hospitalization or shortly after discharge. In our study, almost two-third of suicides were attempted after tree weeks of treatment and hospitalization, which is in accordance with results of Vrapce study ${ }^{[1]}$. A large 
proportion of suicides among schizophrenics occur during or shortly after hospitalization ${ }^{[26]}$. Allebeck and Wistedt ${ }^{[27]}$ found that 34 of 63 suicides took place during or shortly after psychiatric care. Hu and co workers ${ }^{[28]}$ found that $81.1 \%$ of Taiwanese schizophrenic individuals who committed suicide were engaged in either inpatient or outpatient treatment during their final month of life, and $31 \%$ of suicides occurred while the patient was receiving inpatient psychiatric care. In a Finnish sample, $45(51 \%)$ of 89 schizophrenics who committed suicide had their last contact with a health care provider

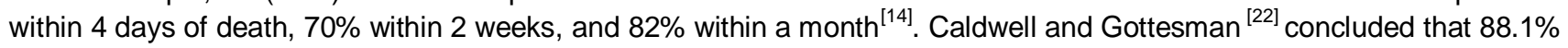
of schizophrenics who committed suicide were in psychiatric care at the time of attempt.

We agree with conclusion of Brecic et al ${ }^{[1]}$, that the variability in methodology used in similar studies limits comparison of results. This is the basic problem in the field of suicide research and the reason why no relevant and reliable predictive factors of suicide risk assessment have been identified. It is also an aggravating circumstance regarding the problem of suicide prevention. The number of suicide attempted during the hospitalization and after has been increasing in the last years, which represents a paradox given the progress in the field of pharmacotherapy and psychotherapeutic techniques. The possible reason could be shorter hospitalizations, larger and faster patient turnover, changes of custodial approach into much more liberal treatment regimes, numerous hospitalizations, and inadequate care in the community, the services of which have not kept up with radical changes in health system ${ }^{[1,3]}$. As Brecic et al ${ }^{[1]}$ said that suicide in psychiatric hospitals is a reality, which should be accepted as such, but reconciled with. The first and foremost reason of reducing the suicide is not to avoid legal responsibility, but to protect life as such. Methodical assessment of suicidal ideation and aggressive treatment with psychological, social, and pharmacological approaches are vital aspects of patient management.

Conclusion: Based on the investigation of patients with schizophrenia who attempted suicide, we obtained a typical profile as follows: middle-aged person, single, unemployed, repeatedly hospitalized and history of suicide attempts, attempting suicide using a violent method after more than tree weeks of hospital treatment and out of hospital.

\section{REFERENCES}

[1] Brecic P., Ostoijc D., Vidovic D et all.. 2009, Characteristics of patients who attempted suicide during hospitalization in Psychiatric hospital "Vrapce" in the period 1996-2006,Coll.Antropol.33, 1:233-236.

[2] Gordon H., 2002, Advances in psychiatric treatment, 8,408.

[3] Smalc VF., Henigsberg N., 2002, Pharmacotherapy of suicidality in schizophrenic patients, MEDICUS, Vol.11, no.2, 177-182.

[4] Kovacic DK., Jendricko T., 2004, Suicidality and depression, MEDICUS, Vol. 13, No1, 77-87.

[5] Conwell Y, Duberstein PR, Cox C, et al, 1996, Relationships of age and axis I diagnoses in victims of completed suicide: A psychological autopsy study. Am J Psychiatry 153:1001-1008.

[6] Newman SC, Bland RC:, 1991, Mortality in a cohort of patients with schizophrenia: A record linkage study. Can J Psychiatry 4:239-245.

[7] Goldstein JM, Santangelo SL, Simpson J, et al, 1993, Gender and mortality in schizophrenia: Do women act like men? Psychological Med 23:941-948.

[8] Ivezic SS., Johan N., 2009, Gender and schizophrenia, Psychiatria danubina, Vol.21, Suppl. 1, pp106-110.

[9] Fenton WS, McGlashan TH, Victor BJ, et al:,1997, Symptoms, subtype, and suicidality in patients with schizophrenia spectrum disorders. Am J Psychiatry 154:199-204.

[10] Fenton WS, McGlashan TH:, 1991 Natural history of schizophrenia subtypes, I: Longitudinal course of paranoid, hebephrenic, and undifferentiated schizophrenia. Arch Gen Psychiatry 48:969-977.

[11] Fenton WS, McGlashan TH:, 1991, Natural history of schizophrenia subtypes, II: Positive and negative symptoms and long-term course. Arch Gen Psychiatry 48:978-986.

${ }^{[12]}$ Cheng KK, Leung CM, Lo WH, et al., 1999, Risk factors of suicide among schizophrenics. Acta Psychiatr Scand $81: 220-224$.

[13] Roy A: Suicide in schizophrenia, in Roy A (ed), 1996,: Suicide. Baltimore, Williams \& Wilkins, pp 97-112.

${ }^{[14]}$ Heila H, Isometsa ET, Henriksson MM, et al., 1997, Suicide and schizophrenia: A nationwide psychological autopsy study on age- and sex-specific clinical characteristics of 92 suicide victims with schizophrenia. Am J Psychiatry 154:12351242.

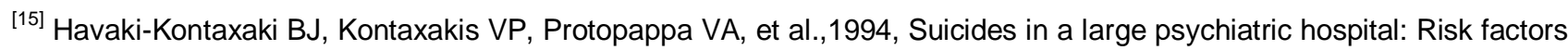
for schizophrenic patients. Bibl Psychiatr 165:63-71.

[16] Allebeck P., 1999, Schizophrenia: A life-shortening disease. Schizophr Bull 15:81-89. 
[17] Allebeck P, Varla A, Kristjansson E, et al.,1997 Risk factors for suicide among patients with schizophrenia. Acta Psychiatry Scand 76:414-419.

${ }^{[18]}$ Drake RE, Gates E, Cotton PG, et al., 1994, Suicide among schizophrenics: Who is at risk? J Nerv Ment Dis 172:613617.

${ }^{[19]}$ Westermeyer JF, Harrow M: Early phases of schizophrenia and depression: Prediction of suicide, in Williams R, Dalby JT (eds), 1999, Depression in Schizophrenics. New York, Plenum Press, pp 153-169.

[20] Tsuang MA, Woolson RF, Fleming JA, 1980, Premature deaths in schizophrenia and affective disorders: An analysis of survival curves and variables affecting the shortened survival. Arch Gen Psychiatry 37:979-983.

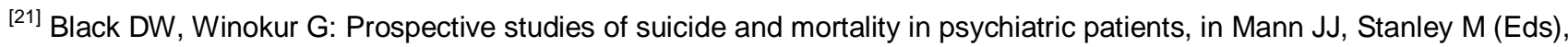
1996, Psychobiology of Suicidal Behavior. New York, N.Y. Academy of Sciences, pp 106-113.

[22] Caldwell CB, Gottesman II, 1990 Schizophrenics kill themselves, too: A review of risk factors for suicide. Schizophr Bull 16:571-589.

[23] Caldwell CB, Gottesman II, 1992, Schizophrenia - A high-risk factor for suicides: Clues to risk reduction. Suicide Life Threat Behav 22:479-493.

[24] Westermeyer JF, Harrow M, Marengo JT, 1991, Risk for suicide in schizophrenia and other psychotic and non psychotic disorders. J Nerv Ment Dis 179:259-266.

[25] Potkonjak J., Karlovic D.,2008, Sociodemographic and medical characteristics of involuntary psychiatric inpatientsretrospective study of five-year experience with Croatian act on mental health, Acta Clin Croat, 47:141-147.

[26] Siris SG, Mason SE, Shuwall MA,1993, Histories of substance abuse, panic and suicidal ideation in schizophrenic patients with histories of post-psychotic depressions. Prog Neuropsychopharmacol Biol Psychiatry 17:609-617.

[27] Allebeck P, Wistedt B, 1996, Mortality in schizophrenia: A ten-year follow-up based on the Stockholm County Inpatient Register. Arch Gen Psychiatry 43:650-653.

[28] Hu W, Sun D, Lee C, et al, 1991, A clinical study of schizophrenic suicides: 42 cases in Taiwan. Schizophrenia Res 5:43-50.

\section{Tables and chart}

Table 1- Patients with suicide attempts in the group of patients with schizophrenia

Suicide attempts No \%

yes $\quad 5447.4$

no $\quad 6052.6$

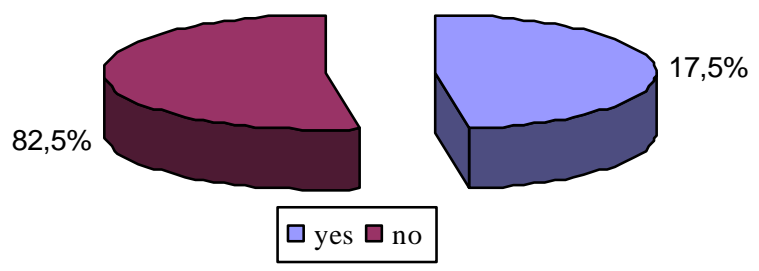

Figure 1 Patients with suicide attempts in the group of patients with schizophrenia 
Table 2- Characteristics of patients $(\mathrm{N}=114)$ who attempted suicide and patients with out

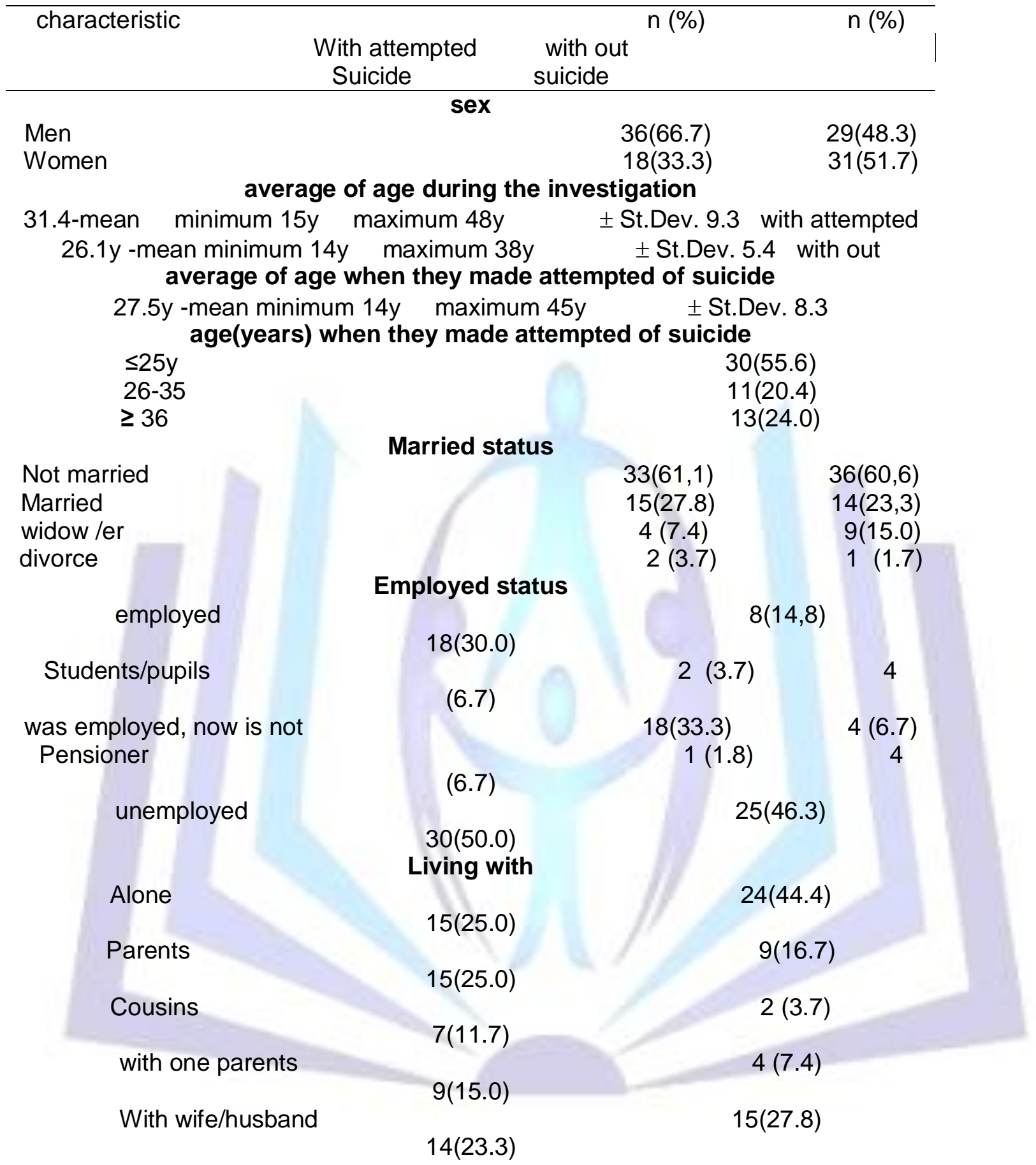

Table 3- Characteristics of 54 patients who attempted suicide and 60 patients with out

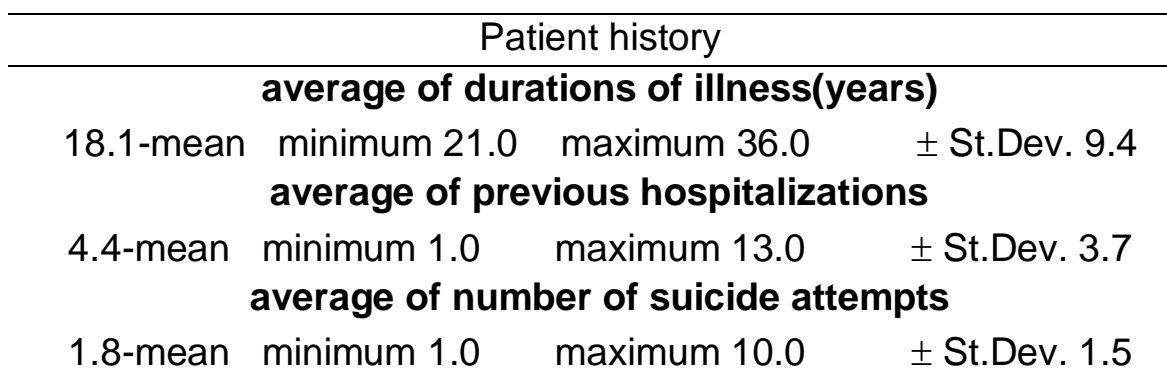




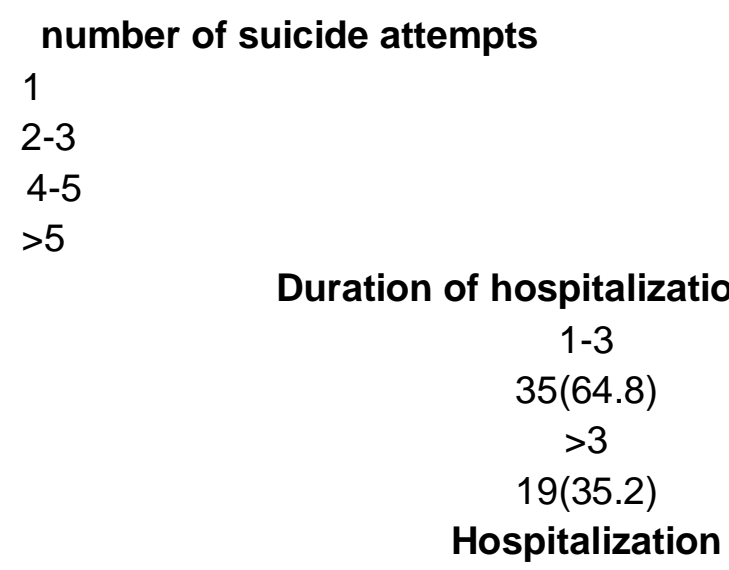

Voluntary

$39(72.6)$

Involuntary

15(27.8)

Clinical type of schizophrenia

n (\%)

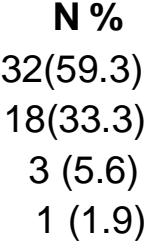

with

with

out suicide suicide

Paranoid

23(42.6)

Hebephrenic

Non-difference

12(22.2)

Residual

12(22.2)

others

Non-specific

Suicide methods

Slashing their wrists

Hanging

Jumping in front of vehicle(car, bus, train)

Jumping from height

(3.7)

Drowning

$3(5.6)$

$9(16.7)$

5

9(15.0)

4

$12(20,0)$

9(15.0)

9(15.0)

2

$3(5.0)$

1

$\%$

5

Drowning

(7.4)

Electric current

3

(5.6)

Stabbing him/herself with knife

Poisoning (medicaments, acid)

32(59.3)

History of suicidal behaviour

$\mathrm{N} \%$

Positive family

$5(9.3)$ 